\title{
"NAD-capQ" detection and quantitation of NAD caps
}

\author{
EWA GRUDZIEN-NOGALSKA, ${ }^{1}$ JEREMY G. BIRD, ${ }^{2}$ BRYCE E. NICKELS, ${ }^{2}$ and MEGERDITCH KILEDJIAN ${ }^{1}$ \\ ${ }^{1}$ Department of Cell Biology and Neuroscience, Rutgers University, Piscataway, New Jersey 08854, USA \\ ${ }^{2}$ Department of Genetics and Waksman Institute, Rutgers University, Piscataway, New Jersey 08854, USA
}

\begin{abstract}
RNA 5' cap structures comprising the metabolic effector nicotinamide adenine dinucleotide (NAD) have been identified in diverse organisms. Here we report a simple, two-step procedure to detect and quantitate NAD-capped RNA, termed "NAD-capQ." By use of NAD-capQ we quantitate NAD-capped RNA levels in Escherichia coli, Saccharomyces cerevisiae, and human cells, and we measure increases in NAD-capped RNA levels in cells from all three organisms harboring disruptions in their respective "deNADding" enzymes. We further show that NAD-capped RNA levels in human cells respond to changes in cellular NAD concentrations, indicating that NAD capping provides a mechanism for human cells to directly sense and respond to alterations in NAD metabolism. Our findings establish NAD-capQ as a versatile, rapid, and accessible methodology to detect and quantitate 5'-NAD caps on endogenous RNA in any organism.
\end{abstract}

Keywords: NAD cap; NAD-capQ; mRNA deNADding; mRNA decapping

\section{INTRODUCTION}

The chemical nature of the $5^{\prime}$ end of RNA is a key determinant of all aspects of mRNA metabolism-synthesis, nucleo-cytoplasmic transport, translation, and turnover (Muthukrishnan et al. 1975; Furuichi et al. 1977; Konarska et al. 1984; Drummond et al. 1985). Thus, cellular processes that alter the chemical nature of the $5^{\prime}$ end of RNA provide a layer of "epitranscriptomic" regulation. One wellcharacterized RNA 5 ' end modification is the 7-methylguanylate $\left(m^{7} \mathrm{G}\right)$ "cap" structure that is added to many eukaryotic messenger RNAs after transcription initiation by a capping complex that binds RNA polymerase II (RNAP II) and interacts with nascent RNA (Shuman 1995). $m^{7} G$ capping protects eukaryotic mRNA from exonuclease digestion, and enables binding of proteins that facilitate mRNA translation and RNA processing.

Recently, a new form of RNA 5' capping was identified (Jäschke et al. 2016; Kiledjian 2018) on bacterial (Chen et al. 2009; Cahová et al. 2015), yeast (Walters et al. 2017), and human (Jiao et al. 2017) RNA species. In this form of RNA 5' capping, nicotinamide adenine dinucleotide (NAD), a critical redox cofactor present in all organisms, is used as a noncanonical initiating nucleotide (NCIN) by RNAP to generate the NAD cap (Bird et al. 2016). NCIN-mediated NAD capping has been demonstrated for bacterial RNAP and eukaryotic RNAP II (Malygin and Shemyakin 1979; Bird et al. 2016; Julius

Corresponding author: kiledjian@biology.rutgers.edu

Article is online at http://www.rnajournal.org/cgi/doi/10.1261/rna. 067686.118. and Yuzenkova 2017), suggesting NAD capping is likely a shared property of all RNAPs. Moreover, mammalian cells appear to also harbor an additional mode of NAD capping that occurs post-transcriptionally (Kiledjian 2018). Thus, in contrast to $m^{7} G$ capping, which occurs only in organisms carrying specialized capping enzymes, NAD-capping, which can be added by RNAP, likely occurs in all organisms. Utilization of NAD as an RNA cap might provide a direct mechanism by which alterations in cellular NAD metabolism can be linked to alterations in gene expression. Studies of NAD capping may represent a new frontier for understanding the interplay between cellular metabolism and RNA biology.

Two methods for detection of NAD-capped RNAs in cells have been reported. The first method involves enrichment of small RNA products by size-exclusion chromatography, enzymatic RNA hydrolysis of the isolated small RNA fraction to completion, and detection of free NAD generated upon hydrolysis by comparative high-resolution LC/MS (Chen et al. 2009). The second method, termed NAD-captureSeq (Cahová et al. 2015; Winz et al. 2017), involves chemoenzymatic modification of the terminal nicotinamide to an alkyne moiety amendable to clickchemistry-mediated biotinylation, isolation of biotinylated RNA by a streptavidin matrix, and analysis of the isolated

(C) 2018 Grudzien-Nogalska et al. This article is distributed exclusively by the RNA Society for the first 12 months after the full-issue publication date (see http://rnajournal.cshlp.org/site/misc/terms.xhtml). After 12 months, it is available under a Creative Commons License (Attribution-NonCommercial 4.0 International), as described at http:// creativecommons.org/licenses/by-nc/4.0/. 
RNA by high-throughput sequencing. Both of these methods are labor-intensive, time consuming, and require specialized laboratory equipment and reagents. We therefore sought to develop an alternative method for detection of NAD-capped RNA that would overcome these limitations.

\section{RESULTS}

\section{NAD cap detection and quantitation (NAD-capQ)}

To develop a simple and rapid method to detect and quantitate levels of NAD caps in cells, we built on the approach developed by Liu and coworkers (Chen et al. 2009) by replacing the mass spectrometry analysis with a versatile colorimetric assay. Our method, termed NAD cap detection and quantitation (NAD-capQ), is a two-step procedure consisting of enzymatic treatment of RNA with nuclease P1 to cleave the phosphodiester bonds within RNA and release 5'NAD, followed by quantitation of released 5'-NAD by a commercially available colorimetric assay (Fig. 1A). The colorimetric assay is based on an enzymatic cycling reaction in which NAD is reduced to NADH, which further reacts with the probe to produce a product that absorbs light at a wavelength of $450 \mathrm{~nm}$, which can be monitored by spectrophotometry (Fig. 1A).

To validate NAD-capO as a method for detection and quantitation of NAD caps, we generated NAD-capped RNA in vitro, incubated different amounts of the RNA with or without nuclease P1, carried out the enzymatic cycling reaction and measured the absorbance in each sample at $450 \mathrm{~nm}$. The signal detected in samples treated with nuclease P1 was above background levels of absorbance detected in samples without nuclease P1 and increased proportionally to the amount of input NAD-capped RNA (Fig. 1B, red bars). In contrast, the signal detected in samples containing a guanosine-capped RNA (Gppp-RNA) was indistinguishable with or without nuclease P1 treatment
(Fig. 1B, green bars), indicating that the signal detected in the analysis of NAD-capped RNA is derived from released NAD. To confirm the signal detected in samples containing NAD-capped RNA was derived from the 5'NAD cap, RNA was treated with Schizosaccharomyces pombe Rai1, a "deNADding" enzyme that hydrolyzes
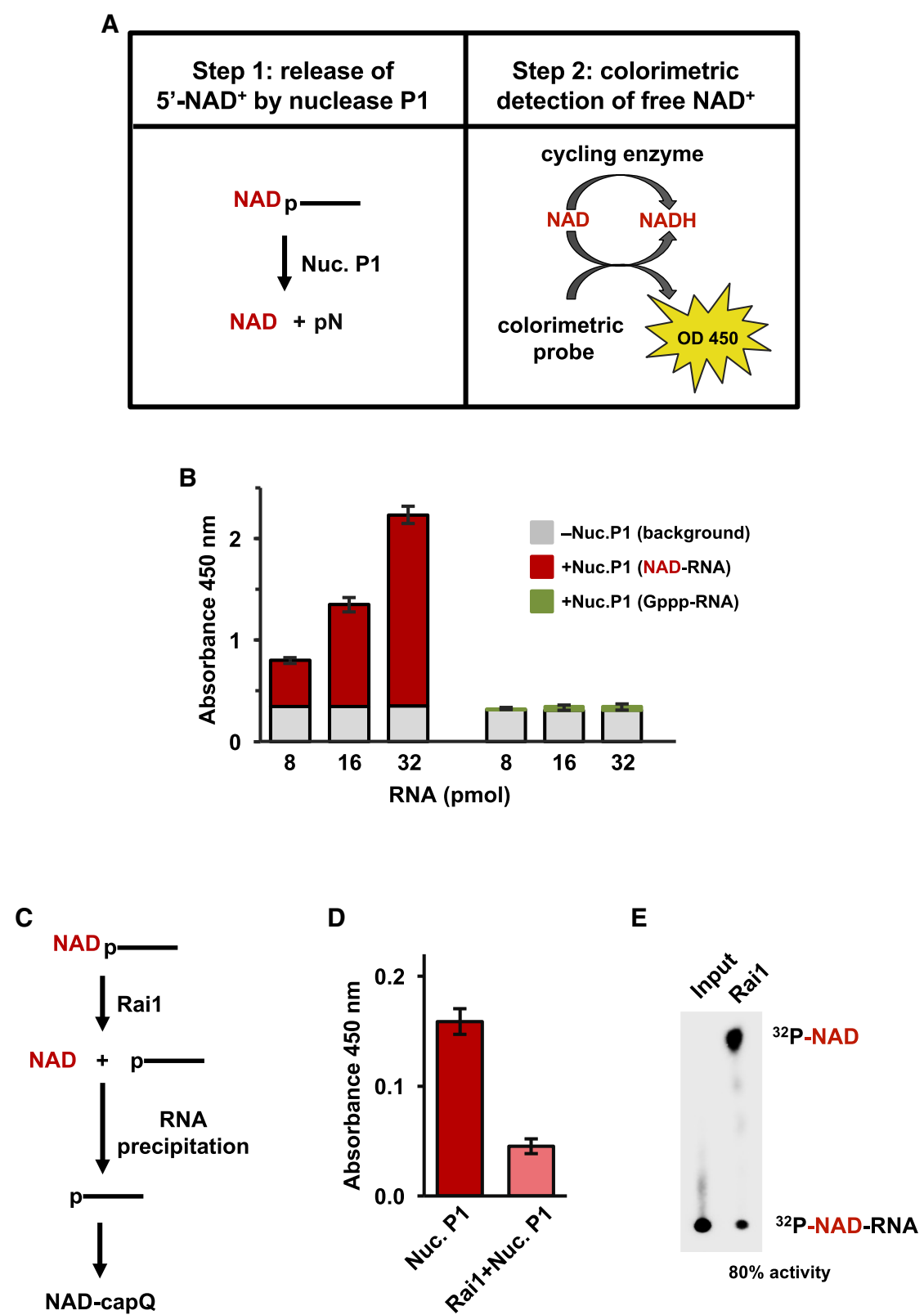

FIGURE 1. NAD-cap detection and quantitation assay. (A) Steps in NAD-capQ. (B) NAD-capQ analysis of RNA generated in vitro. (Red) NAD-RNA; (green) Gppp-RNA; (gray) background signal detected without nuclease P1. Error bars represent $\pm S D, n \geq 3$. (C) Schematic of $5^{\prime}-N A D$ cap removal from NAD-capped RNA using pretreatment with Rai1. (D) NAD-capQ analysis with or without pretreatment of NAD-RNA with Rai1. (Dark red) Background corrected absorbance without Rai1; (light red) background corrected absorbance with Rai1. Significance as in B. (E) Thin-layer chromatography analysis revealing $80 \%$ efficiency of Rai1 hydrolysis of ${ }^{32} \mathrm{P}-5^{\prime}$ end labeled NAD-capped RNA spiked into $50 \mu \mathrm{g}$ total RNA. 
NAD caps without degrading the RNA body (Jiao et al. 2017) to remove NAD caps prior to nuclease P1 digestion (Fig. 1C). Treatment of NAD-capped RNA with Rai1 preceding RNA isolation and nuclease P1 treatment resulted in an $\sim 80 \%$ decrease in the signal detected by NADcapO (Fig. 1D), which matched the $80 \%$ Rai1 efficiency detected by thin-layer chromatographic analysis using radiolabeled NAD-capped RNA (Fig. 1E). The results indicate the signal detected by NAD-capO is derived from $5^{\prime}$-NAD caps. Collectively, the results presented in Figure 1 establish NAD-capQ as a method for the detection and quantitation of NAD-capped RNA generated in vitro.

\section{Quantitation of NAD-capped RNA in diverse organisms by NAD-capQ}

To establish the functionality of NADcapO on endogenous NAD-capped RNAs, we initially tested the method on RNA from E. coli. Plotting the colorimetric signal detected in the analysis of cellular RNA against a standard curve generated using $\mathrm{NADH}$, $\sim 6$ pmol NAD caps were detected per $50 \mu \mathrm{g}$ of total E. coli RNA (Fig. $2 \mathrm{~A}$, orange data-point). Using an estimate of $60 \mathrm{fg}$ RNA per E. coli cell, the value we measured by NAD-capO corresponds to $\sim 4300$ total molecules of NAD cap per cell (Fig. 2B), a value similar to that reported by Liu and coworkers using the LC/MS method ( 3300 NAD cap molecules per cell [Chen et al. 2009]). The corresponding values between NAD cap levels derived from the NAD-capQ assay and that obtained by mass spectrometry demonstrate the validity of NADcapQ for NAD cap quantitation. We conclude that NAD-capQ enables detection and quantitation of NADcapped RNA generated in vivo.

To assess the versatility of the NADcapO assay, we next used NAD-capO to analyze levels of total NAD-capped RNA in yeast and human cells (Fig. 2A, $B)$. We find that $S$. cerevisiae cells contain $\sim 4$ pmol NAD caps per $50 \mu \mathrm{g}$ of total RNA (Fig. 2A, purple data-point) while human HEK293T cells contain $\sim 1$ pmol of NAD caps per $50 \mu \mathrm{g}$ of total RNA (Fig. 2A, blue data-point). The results establish use of NAD-capQ to quantitate levels of NAD-capped RNA across a range of organisms, and suggests a hierarchal distribution of levels of NAD caps in bacteria, fungi, and human cells (Fig. 2A).

\section{Disruption of "deNADding" enzymes alters NAD-capped RNA levels}

To establish use of NAD-capO to quantitate changes in levels of NAD-capped RNA in vivo, we measured levels of NAD-capped RNA in E. coli, S. cerevisiae and HEK293T cells harboring disruptions in their respective "deNADding" enzymes (Kiledjian 2018), and compared these values to levels of NAD-capped RNA in corresponding wild-type cells.

The E. coli NudC protein has been shown to function as a deNADding enzyme in vitro (Cahová et al. 2015).

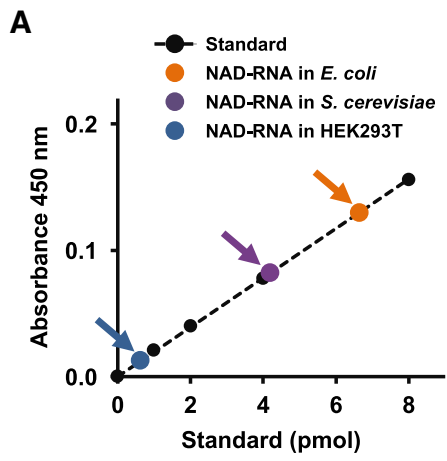

B
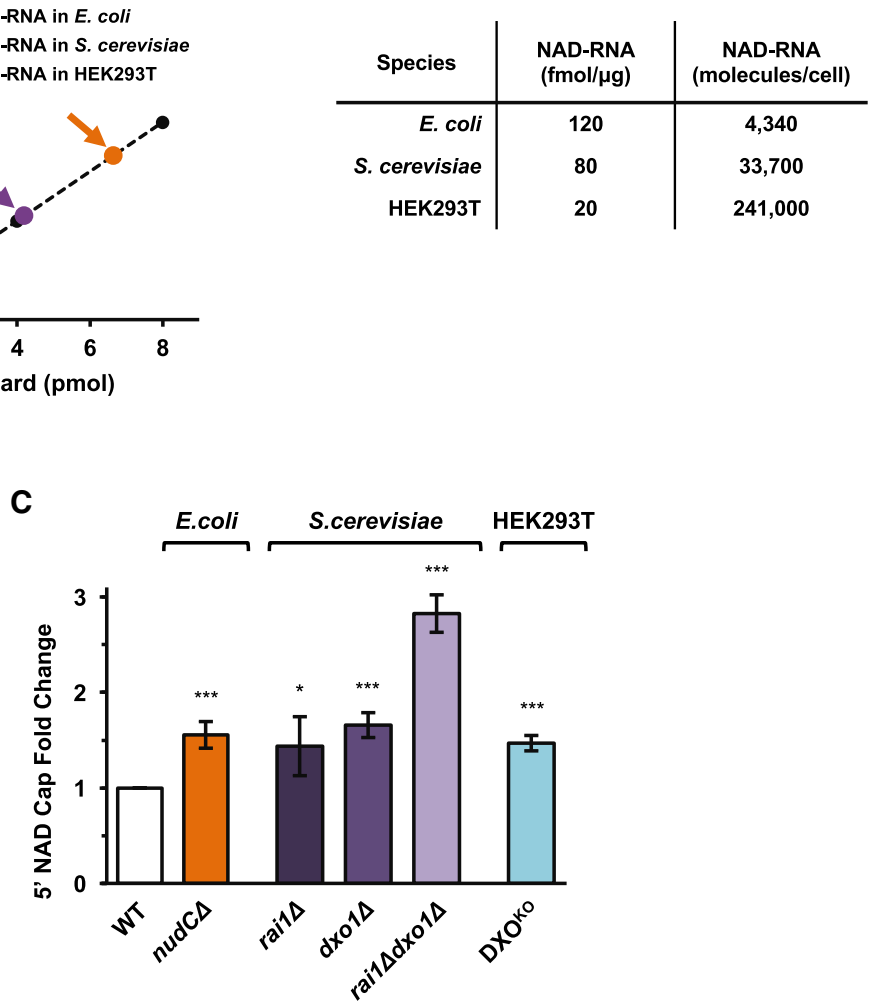

FIGURE 2. NAD-capQ detection and quantitation of RNA generated in vivo. (A) Quantitation of cellular NAD-capped RNA levels in E. coli, S. cerevisiae, or human HEK293T cells plotted on an NADH standard curve (orange data-point, E. coli; purple data-point, S. cerevisiae; blue data-point, human HEK293T; black data-points, NADH standard). $n \geq 3$. (B) Values of NADRNA fmol/ $\mu \mathrm{g}$ were calculated by dividing the calculated value of NAD-capped RNA detected by NAD-capQ in A by the amount of total cellular RNA analyzed. Quantitative values of NADcapped RNA represented as RNA molecules/cell were calculated using total RNA concentrations per cell in E. coli (0.06 pg; Neidhardt et al. 1990), S. cerevisiae (0.7 pg; von der Haar 2008), and mammals (20 pg; Palazzo and Lee 2015), respectively. (C) Effects of disrupting deNADding enzymes on NAD-capped RNA levels in E. coli, S. cerevisiae, and human HEK293T cells. Graphs plot the fold-change in NAD-capped RNA values in the indicated mutant cells relative to the value observed in wild-type cells. (Error bars represent $\pm \mathrm{SD}, n \geq 3 ;\left[{ }^{*}\right] P$ $<0.05$; [***] $P<0.001$ ). 
Furthermore, levels of NAD capping of the RNAI transcript in E. coli cells are higher in cells lacking NudC compared with wild-type cells (Cahová et al. 2015; Bird et al. 2016), providing evidence that NudC functions as a deNADding enzyme in vivo. NAD-capQ analysis of RNA isolated from wild-type E. coli cells or mutant cells carrying a disrupted nudC allele $(\Delta$ nudC) show that total levels of NAD caps are $\sim 1.6$-fold higher in $\Delta$ nudC cells (Fig. 2C). The results provide further evidence that NudC functions as a deNADding enzyme in vivo, in E. coli.

We have recently demonstrated that mammalian and fungal noncanonical DXO/Rai1 decapping enzymes exhibit robust deNADding activity by removing the entire NAD moiety from the $5^{\prime}$ end of NAD-capped RNA (Jiao et al. 2017). To establish the effect of disruptions in DXO/Rai1 decapping enzymes on NAD cap levels in vivo, we first used NAD-capQ to measure NAD cap levels in wild-type $S$. cerevisiae or mutant strains harboring disruptions in rai1 (rai1 $\Delta), d x o 1(d x o 1 \Delta)$, or both (rai1 $\Delta d x 01 \Delta)$. Results show NAD cap levels are 1.4-fold and 1.7-fold higher in rai1 $\Delta$ and $d x o 1 \Delta$ strains, respectively, relative to wild-type cells (Fig. 2C), indicating both proteins function as deNADding enzymes in vivo, in $S$. cerevisiae. Moreover, we find NAD cap levels are higher in cells lacking both enzymes (rai1 $\Delta d x_{0} 1 \Delta$ ) than in cells harboring disruptions in either rai1 or $d x o 1$ alone. These data suggest that Rai1 $p$ and Dxo1 $p$ each target a distinct set of NAD-capped RNAs in S. cerevisiae cells.

We next used NAD-capQ to measure NAD cap levels in human HEK293T cells that carried either the wild-type or homozygous mutant DXO alleles (DKO ${ }^{\mathrm{KO}}$ [Jiao et al. 2017]). Results show NAD cap levels are 1.5-fold higher in cells harboring a disruption in DXO $\left(\mathrm{DKO}^{\mathrm{KO}}\right)$ relative to cells carrying wild-type DXO alleles (Fig. $2 \mathrm{C}$ ), providing further evidence that DXO functions as a deNADding enzyme in human cells. Together, the analysis of E. coli, S. cerevisiae and HEK293T cells harboring disruptions in their respective "deNADding" enzymes establishes NAD-capQ as a method for quantitative analysis of changes in levels of NAD capping in vivo that occur in response to alterations in the enzymatic processing of NAD caps.

\section{Cellular NAD levels can influence NAD capping}

NAD plays a vital role in energy metabolism in eukaryotic cells by acting as an electron acceptor, becoming reduced through the metabolism of other molecules to form NADH to fuel oxidative phosphorylation. NAD and its metabolites also act as cofactors for a wide range of enzymes, such as sirtuins (Hall et al. 2013), linking cellular metabolism to changes in signaling and transcription events.

The demonstration that NAD functions as an NCIN suggests alterations in levels of free NAD will directly alter levels of NAD-capped RNA. To determine whether there is a correlation between cellular NAD levels and levels of
NAD-capped RNA, we treated human HEK293T cells either with nicotinamide (NAM), which increases cellular levels of NAD (Hong et al. 2016) or FK866, a small molecule inhibitor of NAM phosphoribosyltransferase that reduces intracellular NAD (Khan et al. 2006; Wang et al. 2006; Fig. 3B), and analyzed levels of NAD caps by NAD-capQ. Results show that increasing the cellular levels of NAD leads to a corresponding increase in the levels of NAD-capped RNA, while decreasing the cellular levels of NAD leads to a corresponding decrease in the levels of NAD-capped RNA (Fig. 3C). The results indicate that cellular NAD levels and levels of NAD capped RNA are correlated in human cells, and establish NAD-capQ as a method to analyze the interplay between NAD levels and NAD capping in vivo.

\section{DISCUSSION}

Here we report NAD-capQ, a versatile, rapid and accessible methodology to detect and quantitate $5^{\prime}$-NAD caps on endogenous RNA (Fig. 1). We demonstrate the versatility of NAD-capQ by quantitating NAD-capped RNA levels in bacteria, yeast, and human cells (Fig. 2A,B), measuring increases in NAD-capped RNA levels in cells harboring disrupted "deNADding" enzymes (Fig. 2C), and establishing that levels of NAD-capped RNA are responsive to changes in levels of cellular NAD (Fig. 3).

In contrast to previously reported methods for analysis of NAD-capped RNA, NAD-capQ can be performed in a single day using common laboratory equipment. Strikingly, the results of our quantitative analysis of NADcapped RNA in E. coli by NAD-capQ, in which a commercially available kit is used for the detection of NAD, matched results previously reported using LC/MS for detection of NAD (Fig. 2B; Chen et al. 2009). Thus, NAD-capQ is a simpler procedure for detection of NADcapped RNA that provides sensitivity that matches previously reported methods for analysis of NAD-capped RNA.

The ability to rapidly quantitate NAD cap levels enabled us to readily compare NAD-capped RNA levels between several organisms (Fig. 2A,B). We find that the highest amount of total NAD-capped RNA per unit RNA was detected in E. coli, followed by $S$. cerevisiae and human HEK293T cells (Fig. 2A,B). The difference in NAD-capped RNA observed between $S$. cerevisiae and human cells is consistent with prior studies, indicating that intracellular NAD concentrations in $S$. cerevisiae are higher than in mammalian cells $(\sim 1$ to $\sim 2 \mathrm{mM}$ for $S$. cerevisiae [Lin et al. 2004; Sporty et al. 2008] and 0.2-0.5 mM for mammalian cells [Cantó et al. 2015]).

The broad utility of NAD-capQ was evident from findings in S. cerevisiae where the Rai1 and Dxo1 proteins previously shown to possess deNADding activity in vitro, were shown to function as deNADding enzymes in cells. Whether the doubling of NAD cap levels in strains lacking 


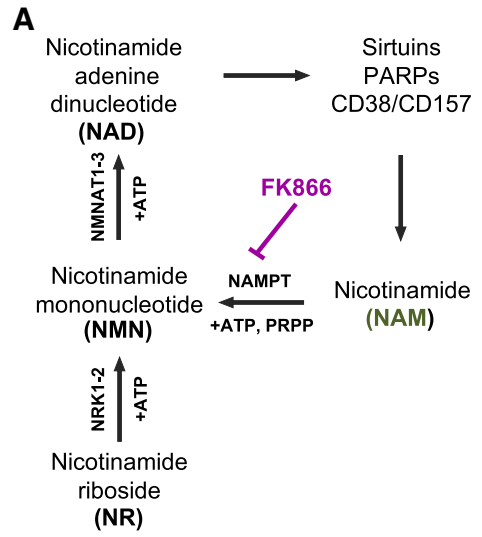

B
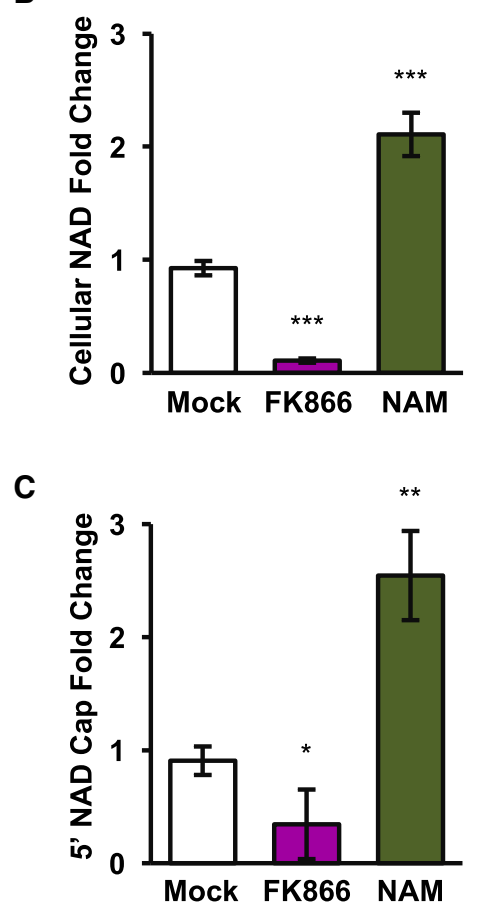

FIGURE 3. Cellular NAD concentrations can influence NAD cap levels. (A) The synthesis of NAD from NAM or NR. NAM is converted to NMN by the rate-limiting NAMPT, using PRPP as a cosubstrate. NMN is also the product of NR phosphorylation by NR kinases. NMN is converted to NAD by the NMNAT enzyme. FK866 is a small molecule inhibitor of NAMPT. (NAMPT) Nicotinamide phosphoribosyltransferase; (NMNAT) NMN adenylyltransferase; (NRK) NR kinase; (PRPP) phosphoribosyl pyrophosphate. (B) Quantitation of cellular total NAD following $48 \mathrm{~h}$ treatment with $5 \mathrm{nM}$ FK866 or $5 \mathrm{mM}$ NAM to decrease and increase cellular NAD levels, respectively. (C) Quantification of NAD-caps, detected with NAD-CapO following $48 \mathrm{~h}$ treatment with $5 \mathrm{nM}$ FK866 or $5 \mathrm{mM}$ NAM. Mean values are plotted. Error bars represent \pm SD. Statistical significance was calculated by one-way ANOVA with a Dunnett's multiple comparison posttest. $P$-values are denoted by asterisks. $(*) P<0.05 ;\left({ }^{* *}\right) P<0.01 ;\left({ }^{* * *}\right)$ $P<0.001$

both enzymes (rai1 $1 \Delta d x 01 \Delta$ ) relative to either alone is due to an additive effect of both enzymes targeting the same NAD-capped RNAs or each enzyme targeting different subsets of NAD-capped RNAs is currently unknown. However, the presence of multiple deNADding enzymes and their potential to target distinct subsets of RNA would be analogous to the multiple canonical $\mathrm{m}^{7} \mathrm{G}$ cap decapping enzymes that function on specific subsets of RNA substrates (Grudzien-Nogalska and Kiledjian 2017) demonstrating a common theme within decapping/deNADding enzymes.

NAD plays a vital role in energy metabolism in eukaryotic cells by acting as an electron acceptor, becoming reduced through the metabolism of other molecules to form NADH to fuel oxidative phosphorylation. NAD also acts as a cofactor for a wide range of enzymes, such as sirtuins (Hall et al. 2013), linking cellular metabolism to changes in signaling and transcription events. In addition, intracellular concentrations of NAD fluctuate along with the metabolic state of a cell and under cellular stress (Chen et al. 2008; Fulco et al. 2008; Cantó et al. 2009, 2010; Raynes et al. 2013). Our finding that, in human cells, alterations in NAD concentrations lead to corresponding alterations in NAD capping suggests NAD capping provides a mechanism by which human cells could directly sense and respond to alterations in NAD metabolism. The results presented here underscore the utility of NAD-capQ in providing a simple quantitative assay to assess the interplay between cellular metabolism and NAD capping.

Although the recent emphasis in the field has been on 5'-end NAD capped RNA (Jäschke et al. 2016; Kiledjian 2018), nucleotide metabolite modifications at the $5^{\prime}$ end of RNAs likely extend beyond NAD. In this regard, it has been shown that, in addition to NAD, RNAP can use several other nucleoside-containing metabolites as $\mathrm{NCINs}$ during transcription initiation, including desphosphocoenzyme A (dpCoA), FAD, UDP-Glucose, and UDP$\mathrm{N}$-acetylglucosamine (Malygin and Shemyakin 1979; Huang 2003; Bird et al. 2016; Julius and Yuzenkova 2017; Vvedenskaya et al. 2018). Furthermore, evidence for $5^{\prime}$-end dpCoA capped RNA has been reported in E. coli (Kowtoniuk et al. 2009). Thus, we anticipate that by incorporating a different colorimetric or fluorescentbased assay in step 2 of the NAD-capO procedure (see Fig. 1A), it will be possible to develop assays to detect and quantitate RNA species that are capped with nucleoside-containing metabolites other than NAD.

\section{MATERIALS AND METHODS}

\section{Bacteria growth and RNA extraction}

E. coli MG1655 was obtained from the ATCC. MG1655 AnudC: Kan was previously reported (Bird et al. 2016). E. coli MG1655 or MG1655 $\Delta$ nudC:Kan cells were grown overnight and then back diluted 1:100 in $25 \mathrm{~mL} \mathrm{LB}$ (10 g Bacto-tryptone, $5 \mathrm{~g}$ Bactoyeast extract and $10 \mathrm{~g} \mathrm{NaCl}$ per liter) containing $25 \mathrm{\mu g} \mathrm{mL}^{-1}$ 
kanamycin (only for the $\Delta$ nudC:Kan strain) in $125 \mathrm{~mL}$ flasks (Bellco). Cultures were shaken at $220 \mathrm{rpm}$ at $37^{\circ} \mathrm{C}$. When cell density reached an $\mathrm{OD}_{600} \sim 3.4(\sim 8 \mathrm{~h}), 5 \mathrm{~mL}$ of the cell suspension was centrifuged (1 $\mathrm{min}, 10,000 \mathrm{~g}$ at room temperature) to collect cells, supernatants were removed, and cell pellets were rapidly frozen on dry ice. To extract total RNA, frozen pellets were resuspended in $1 \mathrm{ml}$ of TRI Reagent solution (Molecular Research Center). Samples were incubated at $70^{\circ} \mathrm{C}$ for $10 \mathrm{~min}$ and then centrifuged $\left(10 \mathrm{~min}, 21,000 \mathrm{~g}, 4^{\circ} \mathrm{C}\right.$ ) to remove insoluble material. The supernatant was transferred to a fresh tube and $200 \mu \mathrm{L}$ of chloroform was added, samples were mixed by vortexing, and then centrifuged $\left(10 \mathrm{~min}, 21,000 \mathrm{~g}, 4^{\circ} \mathrm{C}\right.$ ). The aqueous phase was transferred to a fresh tube, extracted with acid phenol:chloroform twice (Ambion), and RNA transcripts were recovered by ethanol precipitation, washed with $75 \%$ ethanol at $4^{\circ} \mathrm{C}$ and resuspended in RNase free water (Ambion).

\section{Yeast growth and RNA extraction}

The genotypes of the following Saccharomyces cerevisiae strains used in this study were described previously: ABD1 WT (Schwer et al. 2000), ABD1;rai14, ABD1;ydr370C and ABD1; rai14;ydr370CA (Jiao et al. 2010). Yeast strains were grown in minimal (synthetic defined) media at $30^{\circ} \mathrm{C}$ according to standard protocols. All strains were harvested for the experiments at the end of the exponential phase $\left(\mathrm{OD}_{600}=0.9\right)$ and total RNAs were isolated with the acidic hot phenol method (Köhrer and Domdey 1991).

\section{Mammalian cell culture and RNA extraction}

Human embryonic kidney HEK293T cells were obtained from ATCC. Cells were maintained in DMEM medium (Thermo Fisher Scientific) supplemented with $10 \%$ fetal bovine serum (Atlanta Biologics), and antibiotics (100 units $/ \mathrm{mL}$ penicillin and $100 \mu \mathrm{g} / \mathrm{mL}$ of streptomycin) under $5 \% \mathrm{CO}_{2}$ at $37^{\circ} \mathrm{C}$. The three different monoclonal HEK293T cell lines harboring CRISPR-Cas9n double-nick generated distinct homozygous deletions within the DXO gene genomic region corresponding to its catalytic site have been reported previously (Jiao et al. 2017). Total cellular RNAs were extracted with TRIzol Reagent according to the manufacturer's protocol (Thermo Fisher Scientific).

\section{In vitro transcription of NAD-capped RNAs}

For assays shown in Figure 1B and E, NAD-capped RNA, GpppARNA and ${ }^{32}$ P-NAD-capped RNA were generated by in vitro transcription as previously described (Jiao et al. 2017). Four-hundred nanograms of PCR generated $\$ 2.5 \mathrm{~A}-\mathrm{CA} 2-\mathrm{G} 16$ linear template containing the T7 $\$ 2.5$ promoter (Coleman et al. 2004) that retained the first adenosine at the transcription start site and replaced all other adenosine with uracils, as well as harboring the G16 tract at the $3^{\prime}$ end (Jiao et al. 2017), was subjected to in vitro transcription. Reactions were in $50 \mu \mathrm{L}$ reaction buffer $(10 \mu \mathrm{L} 5 \times$ transcription buffer, $5 \mu \mathrm{L}$ DTT [10 mM], $5 \mu \mathrm{L}$ BSA [10 $\mu \mathrm{g} / \mu \mathrm{L}], 5 \mu \mathrm{L} \mathrm{rNTP}$ Mix [5 mM], $2 \mu \mathrm{L}$ T7 RNA polymerase [Promega], and $1 \mu \mathrm{L}$ RNasin Ribonuclease Inhibitor [40 $\mathrm{U} / \mu \mathrm{L}$, Promega]). To generate ${ }^{32} \mathrm{P}-\mathrm{NAD}$-cap labeled or unlabeled NAD-capped RNAs, rATP was replaced with ${ }^{32} \mathrm{P}-\mathrm{NAD}$ or NAD.
For GpppA-capped RNA, 0.5 mM GpppA (Sigma-Aldrich) was used instead of rATP. Reactions were incubated $90 \mathrm{~min}$ at $37^{\circ} \mathrm{C}$ and then treated with 3 units of DNase RQ1 (Promega) for $20 \mathrm{~min}$ at $37^{\circ} \mathrm{C}$. Samples were extracted with acidic phenol:chloroform and RNA recovered by ethanol precipitation.

\section{Cellular total NAD detection}

HEK293T cells $\left(2 \times 10^{6}\right)$ were seeded in $100 \mathrm{~mm}$ plates a day before the experiment. Actively growing cells were either subjected to $48 \mathrm{~h}$ treatment with $5 \mathrm{nM}$ FK866 (Sigma-Aldrich) or 5 mM NAM (Sigma-Aldrich) to decrease and increase cellular NAD levels, respectively. To measure cellular total NAD levels, 1/5 of the cells were lysed in $400 \mu \mathrm{L}$ of NAD/H Extraction Buffer (NAD/H Quantitation Kit, Sigma-Aldrich) and total proteins were extracted with two freeze/thaw cycles ( $20 \mathrm{~min}$ on dry-ice, $10 \mathrm{~min}$ at RT). Cell lysates were centrifuged at $13,000 \mathrm{~g}$ at $4^{\circ} \mathrm{C}$ for $10 \mathrm{~min}$ and supernatant was taken to measure protein concentration. Ten micrograms of total protein was used to detect cellular NAD according to the manufacturer's protocol (NAD/H Quantitation Kit, Sigma).

\section{NAD-cap detection and quantitation (NAD-capQ)}

To carry out NAD-capQ, it was necessary to minimize copurifying free NAD in the RNA preparation. To remove residual free NAD, purified RNAs were dissolved in $10 \mathrm{mM}$ Tris- $\mathrm{HCl}(\mathrm{pH} 7.5)$ containing $2 \mathrm{M}$ urea. Samples were incubated $2 \mathrm{~min}$ at $65^{\circ} \mathrm{C}$ and immediately precipitated with isopropanol in the presence of $2 \mathrm{M}$ (final concentration) ammonium acetate. Fifty micrograms of total RNA was subjected to NAD-cap Detection and Quantitation (NAD-capQ) assay. In the first step, RNA was digested with $1 \mathrm{U}$ of Nuclease P1 (Sigma-Aldrich) in $20 \mu \mathrm{L}$ reaction containing $10 \mathrm{mM}$ Tris ( $\mathrm{pH} 7.0$ ), $20 \mu \mathrm{M} \mathrm{ZnCl} 2$ at $37^{\circ} \mathrm{C}$ for 20 min to release intact NAD/NADH. The control samples were prepared by incubating $50 \mu \mathrm{g}$ of RNA under the same reaction conditions, except instead of adding nuclease $\mathrm{P} 1$, an equivalent volume of $10 \%$ glycerol (which is what was used to dissolve the enzyme) was added to correct for any potential deviation in background absorbance. Similarly, NADH standard was prepared in the same buffer condition as that for the nuclease $\mathrm{P} 1$ reaction. After at least a $2 \mathrm{~h}$ incubation at room temperature, $30 \mu \mathrm{L}$ of NAD/NADH Extraction Buffer (NAD/NADH Quantitation Kit, Sigma-Aldrich) was added to each sample. In the second step, $50 \mu \mathrm{L}$ samples were used in a colorimetric assay to measure absorbance at $450 \mathrm{~nm}$ according to the manufacturer's protocol (NAD/NADH Quantitation Kit, Sigma-Aldrich). The signal corrected for the background absorbance is proportional to concentrations of NAD and NADH within a sample. Although NAD/NADH Quantitation Kit from SigmaAldrich was used in this study, a number of similar kits are available from other manufacturers and could likely be substituted.

\section{Rai1 digestion}

S. pombe Rai1 was prepared from E. coli strain BL21(DE3) Rosetta using culture and induction procedures, immobilized-metal-ion affinity chromatography on Ni-NTA agarose, and size exclusion chromatography using Sephacryl S-300 as in Xiang et al. (2009). Fifty micrograms of total RNA isolated from cells were spiked 
with synthetic ${ }^{32} \mathrm{P}-5^{\prime}$-end labeled NAD-capped RNA and incubated with $4 \mu \mathrm{g}$ of recombinant SpRai1 in $20 \mu \mathrm{L}$ reaction buffer (10 mM Tris- $\mathrm{HCl}$ [pH 7.5], $100 \mathrm{mM} \mathrm{KOAc,} 2 \mathrm{mM} \mathrm{MgCl}$, 2 mM $\mathrm{MnCl}_{2}$ ) for $1 \mathrm{~h}$ at $37^{\circ} \mathrm{C}$. The reactions were stopped by the addition of $30 \mathrm{mM}$ EDTA and RNAs were extracted with acid phenol:chloroform. Urea (2 $\mathrm{M}$ final concentration) was added, samples were heated at $65^{\circ} \mathrm{C}$ for 2 min and total RNA was recovered by isopropanol precipitation in the presence of ammonium acetate (2 $\mathrm{M}$ final concentration). DeNADding products were resolved by $\mathrm{PEI}$-cellulose TLC plates (Sigma-Aldrich) and developed in $0.5 \mathrm{M} \mathrm{LiCl}_{2}$ in a TLC chamber at room temperature as previously described (Liu et al. 2008). Reaction products were visualized and quantitated with a Molecular Dynamics Phosphorlmager (Storm860) with ImageQuant-5 software.

\section{Statistical analysis}

All statistical parameters are listed in the figure legends and represented as error bars in the figures. Statistical significance level was calculated by one-way ANOVA with a Dunnett's multiple comparison post-test. $P<0.05$ is used to claim statistical significances, which are denoted as follows: $\left(^{*}\right) P<0.05 ;\left({ }^{* *}\right) P<0.01$; $(* * *) P<0.001$.

\section{ACKNOWLEDGMENTS}

This work was supported by National Institutes of Health (NIH) grant GM118059 to B.E.N. and GM126488 to M.K.

Author contributions: M.K. and E.G.N. designed the experiments. E.G.N. carried out all experiments unless otherwise indicated. J.B. provided the RNA isolated from bacterial strains. E.G.N., M.K., and B.E.N wrote the manuscript.

Received June 13, 2018; accepted July 16, 2018.

\section{REFERENCES}

Bird JG, Zhang Y, Tian Y, Panova N, Barvik I, Greene L, Liu M, Buckley B, Krásný L, Lee JK, et al. 2016. The mechanism of RNA $5^{\prime}$ capping with $\mathrm{NAD}^{+}, \mathrm{NADH}$ and desphospho-CoA. Nature 535: 444-447.

Cahová H, Winz ML, Höfer K, Nübel G, Jäschke A. 2015. NAD captureSeq indicates NAD as a bacterial cap for a subset of regulatory RNAs. Nature 519: 374-377.

Cantó C, Gerhart-Hines Z, Feige JN, Lagouge M, Noriega L, Milne JC, Elliott PJ, Puigserver P, Auwerx J. 2009. AMPK regulates energy expenditure by modulating $\mathrm{NAD}^{+}$metabolism and SIRT1 activity. Nature 458: 1056-1060.

Cantó C, Jiang LQ, Deshmukh AS, Mataki C, Coste A, Lagouge M, Zierath JR, Auwerx J. 2010. Interdependence of AMPK and SIRT1 for metabolic adaptation to fasting and exercise in skeletal muscle. Cell Metab 11: 213-219.

Cantó C, Menzies KJ, Auwerx J. 2015. NAD ${ }^{+}$metabolism and the control of energy homeostasis: a balancing act between mitochondria and the nucleus. Cell Metab 22: 31-53.

Chen D, Bruno J, Easlon E, Lin SJ, Cheng HL, Alt FW, Guarente L. 2008. Tissue-specific regulation of SIRT1 by calorie restriction. Genes Dev 22: 1753-1757.

Chen YG, Kowtoniuk WE, Agarwal I, Shen Y, Liu DR. 2009. LC/MS analysis of cellular RNA reveals NAD-linked RNA. Nat Chem Biol 5: 879-881.
Coleman TM, Wang G, Huang F. 2004. Superior $5^{\prime}$ homogeneity of RNA from ATP-initiated transcription under the T7 $\$ 2.5$ promoter. Nucleic Acids Res 32: e14.

Drummond DR, Armstrong J, Colman A. 1985. The effect of capping and polyadenylation on the stability, movement and translation of synthetic messenger RNAs in Xenopus oocytes. Nucleic Acids Res 13: $7375-7394$.

Fulco M, Cen $Y$, Zhao P, Hoffman EP, McBurney MW, Sauve AA, Sartorelli V. 2008. Glucose restriction inhibits skeletal myoblast differentiation by activating SIRT1 through AMPK-mediated regulation of Nampt. Dev Cell 14: 661-673.

Furuichi Y, LaFiandra A, Shatkin AJ. 1977. 5'-Terminal structure and mRNA stability. Nature 266: 235-239.

Grudzien-Nogalska E, Kiledjian M. 2017. New insights into decapping enzymes and selective mRNA decay. Wiley Interdiscip Rev RNA 8: e1379

Hall JA, Dominy JE, Lee Y, Puigserver P. 2013. The sirtuin family's role in aging and age-associated pathologies. J Clin Invest 123: 973-979.

Hong SM, Park CW, Kim SW, Nam YJ, Yu JH, Shin JH, Yun CH, Im SH, Kim KT, Sung YC, et al. 2016. NAMPT suppresses glucose deprivation-induced oxidative stress by increasing NADPH levels in breast cancer. Oncogene 35: 3544-3554.

Huang F. 2003. Efficient incorporation of CoA, NAD and FAD into RNA by in vitro transcription. Nucleic Acids Res 31: e8.

Jäschke A, Höfer K, Nübel G, Frindert J. 2016. Cap-like structures in bacterial RNA and epitranscriptomic modification. Curr Opin Microbiol 30: 44-49.

Jiao X, Xiang S, Oh C, Martin CE, Tong L, Kiledjian M. 2010. Identification of a quality-control mechanism for mRNA 5 '-end capping. Nature 467: 608-611.

Jiao X, Doamekpor SK, Bird JG, Nickels BE, Tong L, Hart RP, Kiledjian M. 2017. $5^{\prime}$ end nicotinamide adenine dinucleotide cap in human cells promotes RNA decay through DXO-mediated deNADding. Cell 168: 1015-1027.

Julius C, Yuzenkova Y. 2017. Bacterial RNA polymerase caps RNA with various cofactors and cell wall precursors. Nucleic Acids Res 45: 8282-8290.

Khan JA, Tao X, Tong L. 2006. Molecular basis for the inhibition of human NMPRTase, a novel target for anticancer agents. Nat Struct Mol Biol 13: 582-588.

Kiledjian M. 2018. Eukaryotic RNA $5^{\prime}$-end $\mathrm{NAD}^{+}$capping and DeNADding. Trends Cell Biol 28: 454-464.

Köhrer K, Domdey H. 1991. Preparation of high molecular weight RNA. Methods Enzymol 194: 398-405.

Konarska MM, Padgett RA, Sharp PA. 1984. Recognition of cap structure in splicing in vitro of mRNA precursors. Cell 38: 731736.

Kowtoniuk WE, Shen Y, Heemstra JM, Agarwal I, Liu DR. 2009. A chemical screen for biological small molecule-RNA conjugates reveals CoA-linked RNA. Proc Natl Acad Sci 106: 77687773.

Lin SJ, Ford E, Haigis M, Liszt G, Guarente L. 2004. Calorie restriction extends yeast life span by lowering the level of NADH. Genes Dev 18: 12-16.

Liu SW, Jiao X, Welch S, Kiledjian M. 2008. Analysis of mRNA decapping. Methods Enzymol 448: 3-21.

Malygin AG, Shemyakin MF. 1979. Adenosine, NAD and FAD can initiate template-dependent RNA synthesis catalyzed by Escherichia coli RNA polymerase. FEBS Lett 102: 51-54.

Muthukrishnan S, Both GW, Furuichi Y, Shatkin AJ. 1975. 5'-Terminal 7-methylguanosine in eukaryotic mRNA is required for translation. Nature 255: 33-37. 
Neidhardt FC, Ingraham JL, Schaechter M. 1990. Physiology of the bacterial cell: a molecular approach. Sinauer Associates, Sunderland, MA.

Palazzo AF, Lee ES. 2015. Non-coding RNA: what is functional and what is junk? Front Genet 6: 2.

Raynes R, Pombier KM, Nguyen K, Brunquell J, Mendez JE, Westerheide SD. 2013. The SIRT1 modulators AROS and DBC1 regulate HSF1 activity and the heat shock response. PLoS One 8: e54364.

Schwer B, Saha N, Mao X, Chen HW, Shuman S. 2000. Structurefunction analysis of yeast mRNA cap methyltransferase and highcopy suppression of conditional mutants by AdoMet synthase and the ubiquitin conjugating enzyme Cdc34p. Genetics 155: 1561-1576.

Shuman S. 1995. Capping enzyme in eukaryotic mRNA synthesis. Prog Nucleic Acid Res Mol Biol 50: 101-129.

Sporty JL, Kabir MM, Turteltaub KW, Ognibene T, Lin SJ, Bench G. 2008. Single sample extraction protocol for the quantification of NAD and NADH redox states in Saccharomyces cerevisiae. J Sep Sci 31: 3202-3211. von der Haar T. 2008. A quantitative estimation of the global translational activity in logarithmically growing yeast cells. BMC Syst Biol 2: 87.

Vvedenskaya IO, Bird JG, Zhang Y, Zhang Y, Jiao X, Barvik I, Krasny L, Kiledjian M, Taylor DM, Ebright RH, et al. 2018. CapZyme-Seq comprehensively defines promoter-sequence determinants for RNA 5' capping with NAD. Mol Cell 70: 553-564.e9.

Walters RW, Matheny T, Mizoue LS, Rao BS, Muhlrad D, Parker R. 2017. Identification of $\mathrm{NAD}^{+}$capped mRNAs in Saccharomyces cerevisiae. Proc Natl Acad Sci 114: 480-485.

Wang T, Zhang X, Bheda P, Revollo JR, Imai S, Wolberger C. 2006. Structure of Nampt/PBEF/visfatin, a mammalian NAD ${ }^{+}$biosynthetic enzyme. Nat Struct Mol Biol 13: 661-662.

Winz ML, Cahová H, Nübel G, Frindert J, Höfer K, Jäschke A. 2017. Capture and sequencing of NAD-capped RNA sequences with NAD captureSeq. Nat Protoc 12: 122-149.

Xiang S, Cooper-Morgan A, Jiao X, Kiledjian M, Manley JL, Tong L. 2009. Structure and function of the $5^{\prime} \rightarrow 3^{\prime}$ exoribonuclease Rat1 and its activating partner Rai1. Nature 458: 784-788. 

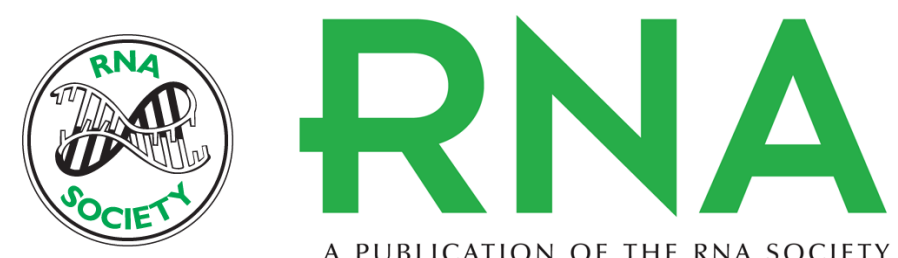

A PUBLICATION OF THE RNA SOCIETY

\title{
"NAD-capQ" detection and quantitation of NAD caps
}

\author{
Ewa Grudzien-Nogalska, Jeremy G. Bird, Bryce E. Nickels, et al.
}

RNA 2018 24: 1418-1425 originally published online July 25, 2018

Access the most recent version at doi:10.1261/rna.067686.118

\section{References This article cites 39 articles, 5 of which can be accessed free at: http://rnajournal.cshlp.org/content/24/10/1418.full.html\#ref-list-1}

Creative This article is distributed exclusively by the RNA Society for the first 12 months after the Commons full-issue publication date (see http://rnajournal.cshlp.org/site/misc/terms.xhtml). After 12 License months, it is available under a Creative Commons License (Attribution-NonCommercial 4.0 International), as described at http://creativecommons.org/licenses/by-nc/4.0/.

Email Alerting Receive free email alerts when new articles cite this article - sign up in the box at the Service top right corner of the article or click here. 